\title{
CRECHES: REALIDADES E NECESSIDADES EM UM MUNDO CONTEMPORÂNEO
}

\section{Dinara Pereira Lemos Paulino da Costa. dinarapereira@uol.com.br}

Resumo: A luta pela qualidade da educação nas creches vem se desenrolando há anos e, ainda hoje, encontra-se em muitas instituições o que ocorria em seus primórdios, ou seja crianças amontoadas em salas mal organizadas e rotinas que não possibilitam o seu bem estar e o seu desenvolvimento pleno. O presente artigo pretende discutir esta caminhada até os dias atuais e apontar alguns elementos sobre a dificuldade que ainda percebemos e a dicotomia existente entre o cuidar e educar.

Palavras chaves: creche, criança, cuidar, educar.

\begin{abstract}
Abstract: The struggle for the quality of education in daycare centers has been unraveling since ages and today there are in many institutes, what used to happen in the beginning, that is, a mass of children in messy rooms and routines which do not offer the welfare and the complete development. The current article aims to discuss this way from the beginning till the present and points out some elements about the difficulty that we still note and the existing dichotomy between caring and educating.
\end{abstract}

Key-words: daycare centers, child, caring, educating.

\section{Introdução}

Pensar nas crianças hoje é pensar imediatamente em pais trabalhando fora para prover esta família de suas necessidades, pensar nas crianças, e nas pessoas que tomam para si a responsabilidade de cuidar delas. Como estão as instituições que cuidam e educam as crianças de 0 a 3 anos hoje? De onde vem a idéia de creche e quais eram seus primeiros objetivos? Que avanços tivemos e que caminhos ainda é preciso percorrer para dar as crianças de fato um ambiente intencionalmente organizado para desafiar seu pensamento e encorajar sua ação, promovendo o seu desenvolvimento de forma integral, segura e feliz?

As famílias contam no mundo de hoje com os berçários e creches para que a auxiliem na função de cuidar e educar os filhos. Como se deu este processo de [Digite texto] Mestre em Educação pela Universidade Estadual de Campinas UNICAMP. Professora Substituta do Curso de Pedagogia CAJ/UFG 
construção de uma escola para crianças tão pequenas? Quais os anseios das famílias? Quem são e quais os desafios para esses profissionais?

Falar das creches é dar uma volta no tempo, quando se relembram seus objetivos iniciais, suas lutas, reivindicações e modificações diversas desde as primeiras instituições que surgiram na França até os nossos dias.

Segundo pesquisas, (Haddad, 1993; Rizzo, 2000; Sanches, 2003), as creches surgiram durante o século XIX, nos países norte-americanos e europeus e, no início do século XX, no Brasil, acompanhando a estruturação do capitalismo, a crescente urbanização e a necessidade de reprodução da força de trabalho composta por seres capazes, nutridos, higiênicos e saudáveis.

Rizzo (2000) considera que a finalidade dessa instituição era o recolhimento de crianças pobres da rua a fim de esconder, assim, da sociedade a miséria existente. Nesse período, o objetivo da creche era ser "provedora de um ambiente sadio", em que as crianças recebiam cuidados assistenciais para que fossem sanadas suas necessidades físicas num ambiente higiênico, atendendo às famílias pobres, sem condições de criar bem seus filhos. As instituições existentes eram filantrópicas, viviam de doações e do trabalho voluntário desqualificado.

Segundo a autora (ibid, p.38), "Qualquer coisa servia para quem já era desvalido mesmo, era o pensamento dominante".

Essa prática deixava claro que a função da creche era cuidar de crianças, cujas mães trabalhavam fora do lar ou não tinham condições financeiras, mas enfatizava-se que a criança se desenvolveria melhor com suas famílias, que deveriam, para essa tarefa ser bem constituídas e estruturadas. Assim, a existência das creches só se justificava para atender à necessidade de mulheres viúvas ou abandonadas que trabalhavam por não terem alternativa, ou para atender a filhos de mulheres julgadas "mães incompetentes".

Essa instituição se caracterizava pela precariedade e insuficiência de recursos, pela má qualidade do atendimento, falta de preparação dos funcionários, muitas vezes, analfabetos e voluntários, e pela ausência de legislação que a integrasse como instituição educativa. Enfim, eram poucos os recursos e espaços a ela designados.

$\mathrm{O}$ antigo paradigma da creche ligada à "falta da família", em muitos lugares, impediu que tivesse identidade própria e projetos de leis que a regulamentasse. Ainda hoje, após a Lei de Diretrizes e Bases para a Educação, esse modelo que visava ao 
assistencialismo e à guarda das crianças permanece em muitas instituições.

Outro motivo da existência das creches relaciona-se a mudanças na estrutura familiar.

Didonet (2001, p.12) propõe que:

\begin{abstract}
A consolidação e a expansão da creche como instituição de cuidados a criança estão associadas também a transformação da família, de extensa para nuclear. Naquela, muitas pessoas podiam ocupar-se dos cuidados com a criança pequena: avó, tia, primos, irmãos maiores. Nessa, ao sair para o trabalho, os pais têm que deixar sua filha, seu filho recém nascido ou ainda bebê, sozinho. Mortalidade infantil elevada, desnutrição generalizada e acidentes domésticos passaram a chamar a atenção e despertar sentimentos de piedade e solidariedade de religiosos, empresários, educadores...
\end{abstract}

Com esse sentimento de "pena" e a necessidade de se fazer algo pelos pequenos, que ainda não eram considerados cidadãos de direito e sujeitos-de-educação, é que as creches foram criadas, com o objetivo de guardar e assistir a criança enquanto a família está fora.

Foram anos voltados a uma prática assistencialista e de cuidados, porém com a mudança na sociedade, a inserção das mulheres no mercado de trabalho, as pesquisas que mostram a criança em uma fase rica do seu desenvolvimento, as creches buscam, em nossos dias, adequarem-se a um novo modelo.

\title{
Desenvolvimento
}

No Brasil esse processo foi iniciado com a Constituição Federal de 1988, na qual a creche já era mencionada: "O dever do estado com a educação será efetivado mediante a garantia de (...) atendimento em creche e pré-escolas as crianças de 0 a 6 anos de idade..."

Posteriormente a Lei de Diretrizes e Bases da Educação Nacional - LDB 9394/96, fixou um prazo de três anos após a sua publicação, para que as creches fossem integradas ao sistema de ensino (art.89), "as creches e pré-escolas existentes ou que venham a ser criadas deverão, no prazo de três anos, a contar da publicação desta lei, integrar-se ao respectivo sistema de ensino." 
Rizzo (2000, p. 49) ressalta que com essa lei, muda-se então, no Brasil, o conceito de creche e também a sua função, sendo esta: "um ambiente especialmente criado para oferecer condições ótimas que propiciem e estimulem o desenvolvimento integral e harmonioso da criança sadia nos seus primeiros três anos de vida". Segundo essa perspectiva, a função dessa instituição não é mais de "guardar as crianças" e, sim, uma função mais ampla que envolve cuidados e educação como intrínsecos e necessários. Nessa nova visão, não devem existir dicotomias, uma vez que o banho, a alimentação, a troca de fraldas e as atividades de desenho, jogo simbólico e linguagem têm a mesma importância.

As creches hoje não são mais "exclusivas" para as crianças pobres e necessitadas, devem ser de fato e de direito de toda e qualquer criança, e sua função deve ir além dos cuidados e do assistencialismo, o que modifica também os seus objetivos, quando passa a ser também educativa e formadora. $\mathrm{O}$ direito das crianças e suas famílias ao atendimento nas creches passa ainda pela dificuldade de encontrar, nas instituições, o número de vagas suficientes. Na maioria das creches a procura é grande, e a lista de espera por uma vaga é significativa. As instituições, apesar de saberem do direito de todas as crianças ao atendimento, muitas vezes, não podem atender à demanda devido a inúmeros fatores como: a falta de espaço físico, de pessoal qualificado e de recursos para alimentação e suprimentos em geral. Nessas condições, a direção realiza uma seleção que, na maioria das vezes prioriza as crianças que possuem maior dificuldade financeira, moradia inadequada, falta de alimentação, dentre outros.

É necessário que a função da creche complemente a da família e que ambas trabalhem juntas para o desenvolvimento da criança.

Rizzo (2000, p.80) fala da necessidade da união entre cuidado e educação de qualidade e ressalta a necessidade de atividades pedagógicas ricas e diversificadas, bem como os cuidados que toda criança requer.

O trabalho da creche e sua responsabilidade consistem em dar espaço, oportunidade e estímulo, de base social-afetiva, para a criança crescer e oferecer situações de sucesso, a fim de que ela possa querer continuar crescendo, de forma natural, segura e feliz. É necessário um trabalho, em parte semelhante ao que ocorre dentro de uma grande família, que acompanha e supervisiona brincadeiras no jardim, banho de sol, brincadeiras com água no quintal, jogos, histórias, desenhos, pinturas e modelagem, bonecas, carrinhos e caminhões, banho, sono e alimentação. As atividades pedagógicas 
devem ser, em tudo, semelhantes a uma boa escola maternal ou de educação infantil, gozando de maior informalidade, devem ser planejadas e controladas com profissionalismo.

Sob essa concepção, a creche precisa desempenhar duas atividades que devem estar vinculadas entre si: proporcionar momentos de interação entre crianças de faixas etárias diferenciadas, possibilitando-lhes brincadeiras que fariam no quintal de casa e ao mesmo tempo ser provedora de um espaço para atividades pedagógicas mais elaboradas.

$\mathrm{Na}$ atualidade, com o crescimento urbano, as necessidades econômicas e políticas, a crescente preocupação com a mudança da sociedade, as pesquisas diversas em relação ao desenvolvimento da primeira infância e a necessidade de se oferecer um ambiente adequado ao desenvolvimento sócioafetivo, intelectual e motor têm mudado o perfil da instituição creche.

Todavia essa mudança na lei, apesar de ser uma conquista, não garante a mudança na concepção dos profissionais que estão ligados à creche e que ainda a vêem como somente assistencialista. Sabemos das necessidades diversas em relação à instituição e a seus profissionais como: salário justo, carga horária, melhores condições de trabalho, recursos materiais, mas enfatizaremos, em nosso artigo, a questão da formação dos educadores e sua prática educativa.

Cada vez mais, é preciso fazer com que a creche seja um lugar educativo e considerar nela educação e cuidados como indissociáveis. Espera-se que, por meio da capacitação de seus profissionais, estes tenham melhores condições para atender as crianças e estimulá-las, a fim de propiciar-lhes um ambiente rico, onde cada faixa etária, com suas especificidades e necessidades, seja respeitada e atendida.

Atualmente, constata-se que algumas creches, devido à sua história e à função exercida durante anos, ainda têm deixado o "educar" de lado e se preocupado somente com a função de cuidar. Situações como essas são observadas em visitas que realizamos a muitas creches municipais, filantrópicas e particulares, as quais mostram a precariedade dos recursos físicos, de pessoal capacitado e, como conseqüência, a ausência de um ambiente, intencionalmente organizado, que vise a estimular o desenvolvimento infantil.

Crianças "amontoadas" em salas mal organizadas passam seus dias em berços, às vezes, mais de 8 horas seguidas, sem o direito de uma vida de acordo com suas necessidades básicas para um bom desenvolvimento psicológico, cognitivo e físico, já [Digite texto] 
que as instituições nem sempre estão preparadas para tal. Os educadores, sem o conhecimento necessário sobre desenvolvimento infantil, realizam seu trabalho da forma que acham correto e pensam estar fazendo um bem, muitas vezes, sem que ninguém lhes auxilie num processo contínuo de reflexão sobre a prática e as conseqüências da mesma na vida das crianças.

Por falta de conhecimentos, não atentam para as conseqüências de deixar crianças de 0 a 15 meses por horas num berço, freqüentemente, para realizarem outras tarefas ou mesmo atender a outro bebê. O número de crianças quase sempre é maior do que a capacidade das instituições e a quantidade de funcionários, devido à falta de recursos, é, em sua maioria, insuficiente.

Encontramos, muitas vezes, nessas instituições, crianças tristes e desanimadas, as quais demonstram, em seus rostos, que poderiam estar fazendo algo mais divertido e interessante do que passar horas, no mesmo lugar, com as mesmas pessoas desmotivadas e as mesmas brincadeiras; enfim, a mesma rotina e uma equipe de funcionários frustrados com sua própria atuação, com a falta de perspectivas e de melhores condições de trabalho.

Em muitas instituições, observamos atividades inadequadas para a idade e interesse das crianças, poucos brinquedos e os mesmos, mal conservados. Não raro, observam-se adultos que, por falta de conhecimentos, tentam disciplinar as crianças por meios de gritos, ameaças e castigos. Em visita a uma creche, um educador oferecia a 12 crianças de 1 ano e meio 20 peças de encaixe gigante as quais eram disputadas por meio de empurrões, tapas e mordidas. A intervenção do educador refletia a falta de conhecimentos sobre o desenvolvimento infantil e as características dessa faixa etária. $\mathrm{O}$ educador preferiu tirar os brinquedos das crianças e levá-las ao solário, quando percebeu os conflitos. Devido à indiferença entre o eu e o outro (egocentrismo), sabemos que as crianças por volta de um ano de idade estão centradas em suas necessidades e desejos. Quando se sentem ameaçadas, ou uma outra criança pega um brinquedo delas, reagem, ou melhor, defendem-se com os recursos que possuem. Nesse caso, a criança empurra ou morde o colega por não saber resolver o conflito de outra forma, além do que não consegue explicar o que está sentindo e dizer que fica brava quando alguém lhe tira um objeto. Assim, os empurrões e as mordidas são meios de comunicação, meios de dizer ao outro que não podem retirar-lhe o objeto. Às vezes, 
observamos uma criança pequena ser colocada no "chiqueirinho" por estar "agredindo" um colega do berçário, ou porque morde muito, ou toma os brinquedos dos outros. Essa prática mostra, novamente, a falta de formação dos educadores e o desconhecimento sobre as características deles.

Faz-se necessário, oferecer nas creches, um ambiente rico em desafios adequados, criar um ambiente sócio-moral cooperativo onde prevaleça o respeito mútuo, e as crianças sejam incentivadas a trocas afetivas e sociais mais ricas, pois,

nós somos aquilo que experenciamos em nossas relações sociais efetivas. É a interação do indivíduo com o meio em que vive, é o sentir de cada criança que vai sendo construído e reconstruído mediante suas experiências positivas e negativas, que influenciarão em sua auto-estima. (La Taille apud VINHA, 2000, p.40).

Atendendo a crianças durante nove e até dez horas diárias, a creche assume um papel importante em suas vidas. Nessa instituição, aprenderão a se relacionar com os iguais vivendo num espaço coletivo; a se alimentar; a cuidar de sua higiene; aprenderão que existem pessoas que se interessam por elas, que as respeitam em suas necessidades e possibilidades e que trabalham para promover situações que lhes favoreçam o desenvolvimento. Além dos cuidados de saúde e alimentação, acrescentam-se as atividades pedagógicas que devem assemelhar-se a uma boa escola maternal, e essas condições devem ser acrescidas de muito afeto, ao mesmo tempo, quando necessário, serem utilizados limites claros e justificados, para que as crianças, aos poucos, aprendam a conviver em um ambiente que tenha como princípios a igualdade, $\mathrm{o}$ respeito, a justiça e a dignidade.

Haddad (1993), ao escrever sobre a realidade da instituição creche em busca de sua identidade, discorre sobre a concepção ingênua que possuíam de que as educadoras eram como uma espécie de substitutas maternas, ou seja, aquelas que cuidam, alimentam, dão banho, dentre outros.

A autora (ibid, p.103) ressalta que o mais importante é a mudança de uma relação afetiva entre adulto e criança para uma função também educativa em parceria com a família.

\footnotetext{
${ }^{1}$ Chiqueirinho: cercado.

[Digite texto]

Mestre em Educação pela Universidade Estadual de Campinas UNICAMP. Professora Substituta do Curso de Pedagogia CAJ/UFG
} 
Durante muito tempo orientamos as pajens para uma relação individualizada, afetiva e compreensiva para com a criança. Além de todas as tarefas rotineiras que tinham de realizar, cabia-lhes conhecer cada criança, discriminar suas necessidades e compreender seus problemas familiares. Para dissimular o fantasma de que a creche prejudica o desenvolvimento infantil, tentávamos transportar uma dimensão familiar a uma dimensão coletiva. $\mathrm{Na}$ verdade atribuíamos às pajens a função de dar afeto às crianças, como uma mãe a seu filho, ignorando o fato de que na espécie humana não existem mães com vinte filhos da mesma idade para criar de uma só vez.

A creche era vista como um segundo lar, um lugar onde as crianças receberiam cuidados e afeto como uma mãe daria a seu filho. Essa idéia de creche como substituta materna contribuía para a prática assistencialista nas instituições. Mais uma vez, para ser profissional de creche, era necessário gostar e saber cuidar de crianças e a dimensão educativa e a formação dos educadores não eram considerados.

Pesquisas recentes da neurociência apontam para a importância da fase de vida de zero a três anos:

O que as pesquisa dizem é que o cérebro se forma na relação da criança com o ambiente, e que isso ocorre principalmente de zero aos 10 anos e de forma ainda mais acentuada do zero aos três. Crianças que têm pouco estímulo na fase inicial da vida, deixam de formar certos "circuitos" no cérebro (ROSSETTI, 1997, C1).

A educação infantil ( 0 a 3 anos) é hoje uma realidade que precisa sair do papel e adentrar-se nas instituições brasileiras, especialmente, creches, já que atendem a crianças por um longo período de tempo em uma das fases importantes da vida. Mais do que oferecer creches, então, é necessário oferecer ás crianças um ambiente intencionalmente organizado e educadores bem preparados.

Shatz (1997, C 1), compara o desenvolvimento cerebral a instalação de uma rede telefônica,

O cérebro tem mais de um trilhão de células nervosas (neurônios). Cada uma é como um telefone que se comunica com outras células por sinais eletroquímicos. "Esses sinais são transmitidos por axônios, que são como linhas telefônicas, emitidas pelo neurônio". Durante o desenvolvimento, o cérebro tem que formar cerca de 100 trilhões de conexões entre os neurônios. Nenhuma dessas conexões está lá desde o início. Há dois fatores determinantes na formação dessas conexões.

[Digite texto]

Mestre em Educação pela Universidade Estadual de Campinas UNICAMP. Professora Substituta do Curso de Pedagogia CAJ/UFG 
O primeiro é genético: os genes dos pais determinam parte da estrutura cerebral da criança. $O$ segundo fator é ambiental: os estímulos que a criança recebe determinam a emissão de axônios e a formação ou não de uma conexão.

Os estímulos na creche devem ser especialmente cuidados pelos educadores, as quais devem pensar em pequenos desafios para as crianças e os bebês presentes no cotidiano. É necessário que as crianças se deparem, nesse ambiente, com solicitações que lhes possibilitem construir seus conhecimentos e estabelecer mais e novas relações entre objetos e pessoas, que encontrem "alimentos" para a formação de novas conexões cerebrais, já que se acham numa fase essencial para o desenvolvimento intelectual, afetivo, físico e social.

Para esse trabalho com os pequenos, deve haver pessoas especializadas, interessadas e comprometidas para que, juntas, propiciem as melhores condições possíveis para o desenvolvimento infantil e deixem de reproduzir o que já temos.

Piaget (1973, p.25) afirma que,

A preparação dos professores constitui a questão primordial de todas as reformas pedagógicas, pois enquanto não for a mesma resolvida de forma satisfatória, será totalmente inútil organizar belos programas ou construir belas teorias a respeito do que deveria ser realizado (...). A única solução racional: uma formação universitária completa para os mestres de todos os níveis pois, quanto mais jovens são os alunos, maiores dificuldades assume o ensino, se levado a sério a semelhança da formação dos médicos, etc.

Sabemos que, sem formação inicial e continuada, dificilmente é possível realizar um trabalho pedagógico competente e obter bons resultados, assim como fazer pelas crianças o melhor para que desenvolvam suas possibilidades.

Pesquisas diversas tais como: a de Haddad (1993), a de Rizzo (2000), e de Sanches (2003) têm diagnosticado a realidade que se vivencia nas creches e apontado caminhos que auxiliem os educadores na ressignificação de suas práticas de cuidados e de educação.

Para Haddad (2003, p.17) é necessária uma mudança de paradigma,

tenho defendido a expressão "educação e cuidado infantil" como um terceiro modelo, que indica a necessidade de uma aproximação entre 
as dimensões sociais e educacionais do atendimento em uma atenção conjunta as necessidades da criança e da família no contexto da modernidade. Esse novo modelo, construído a partir da remoção das inconsistências dos modelos anteriores de cuidado assistencial e educação pré-escolar e do reconhecimento de suas qualidades, apresenta um novo elemento que vai garantir coesão entre o cuidado e educação: a legitimação da socialização infantil extrafamiliar.

É necessária uma ampliação da visão de educação, ao entendê-la como uma forma de humanização onde não existem dicotomias nas ações com as crianças pequenas e, sim, um processo intenso e único de desenvolvimento.

\section{Considerações finais}

Para oferecermos as crianças uma educação nas creches que de fato favoreça o seu desenvolvimento e sua emancipação enquanto um ser humano seguro e feliz é preciso pensar e investir no profissional que lá está. Pensar em cursos de curta e longa duração, em horários que sejam possíveis para que estes profissionais possam e se interessem em participar. É preciso perguntar a elas, ouvi-las sobre suas angústias, dúvidas, necessidades e vontades. O que querem aprender, estudar, quais as suas demandas? Sabemos que os cursos de formação são condições necessárias para uma boa formação profissional, mas, não suficientes, pois é preciso que este profissional se envolva, que queira aprender para fazer melhor para si mesmo e para as crianças.

Segundo os Referenciais para a Formação de Professores (1999, p. 64):

A própria natureza do trabalho educativo exige que o movimento de contínua construção e reconstrução de conhecimento e de competências profissionais, vivenciado na formação inicial, prolongue-se ao longo da carreira de professor. Ainda que a formação inicial seja um importante e insubstituível meio de elevar o nível e de transformar a competência dos futuros professores, essa possibilidade tem limites.

Defender a idéia da formação em serviço, do planejamento consciente dos gestores que tem a seu cargo gerir uma instituição como as creches. Dialogar com os pais, mostrando com resultados a necessidade da formação continuada das educadoras, que também são mães, tem seus filhos, esposos, e suas vidas pessoais e, portanto não podem passar o dia na instituição e voltar para cursos de formação à noite ou aos 
sábados. É preciso prever a formação antes de iniciar o ano e comunicar aos pais no ato da matrícula a proposta pedagógica da creche, e a formação continuada que a instituição oferece aos professores para melhor atender a seus filhos.

O profissional mobiliza um capital de saberes, de saber-fazer e de saber-ser que não estagnou, pelo contrário, cresce constantemente, acompanhando a experiência e, sobretudo, a reflexão sobre a experiência. Aliás, a formação contínua mais eficaz consiste, muitas vezes, em intensificar e fazer partilhar a reflexão sobre a prática. (PERRENOUD,1993, p. 186)

Nas creches é preciso reservar um período semanal para que a coordenação pedagógica sente com esses educadores e faça o exercício da reflexão sobre a ação, que juntos busquem, estudem para que possam ressignificar sua prática por meio da experiência dialogada, estudada e transformada, de que tanto necessitamos para oferecer uma educação de qualidade, que nos dê prazer e traga consequentemente alegria e desenvolvimento pleno às crianças.

É preciso também lutar junto às educadoras por melhores condições de trabalho, salários condignos com a função de cuidar e educar crianças em uma fase de vida crucial para o seu desenvolvimento pleno, seguro e feliz. Pensar sobre o número de crianças por salas e o número de educadores para que atenda bem os meninos e no fím do dia não se sintam enfastiadas e frustradas com o seu dia de trabalho.

\section{Referências Bibliográficas}

DIDONET, V. Creche: a que veio... para onde vai .... In: Em Aberto. Brasília Vol. 18, n.73, Julho, 12-28 p, 2001.

HADDAD, L. A. Creche em Busca de Sua Identidade. Edições Loyola, São Paulo, 1993.

Lei de Diretrizes e Bases da Educação Nacional n 9.394, Editora do Brasil S/A, 20 de Dezembro de 1996.

PIAGET, J. Para onde vai a educação?. Rio de Janeiro: Livraria José Olympio, 1973. PERRENOUD, P. Práticas pedagógicas, profissão docente e formação: perspectivas sociológicas. Lisboa, Publicações Dom Quixote, 1993. 
Referenciais para a Formação de Professores. Secretária de Educação Fundamental Brasília, 1999.

RIZZO, G. Creche: Organização, Currículo, Montagem e Funcionamento. Bertrand Brasil Editora, Rio de Janeiro, 2000.

ROSSETTI, F. Ciência do cérebro altera visão do ensino. Folha de São Paulo, 21 de Abril, 1997.

SANCHES, E. C. Creche: realidade e ambigüidades. Petrópolis, RJ, Vozes, 2003.

SHATZ, C. Estímulo deve seguir bom senso. Folha de São Paulo, 21 de Abril, 1997.

VINHA, T. P. O Educador e a Moralidade Infantil. Uma Visão Construtivista. Campinas. Mercado de Letras, 2000. 